\title{
Schistosomiasis Mansoni among School Children of Different Water Source Users in Tigray, Northern Ethiopia
}

\author{
Tadesse Dejenie $^{1 *}$ and Tsehaye Asmelash ${ }^{2}$ \\ ${ }^{1}$ Department of Biology, College of Natural and Computational Sciences, Mekelle University, \\ PO Box 231, Mekelle, Ethiopia (*taddej2002@gmail.com) \\ ${ }^{2}$ Department of Microbiology and Immunology, College of Health Sciences, Mekelle University, \\ PO Box 1871, Mekelle, Ethiopia
}

\begin{abstract}
The current trend of harvesting water to supplement the agricultural productivity is associated with the expansion of schistosomiasis mansoni and other intestinal parasitic infections. Considering this, the present study was started with the objective of assessing the prevalence and intensity of $S$. mansoni infection and other intestinal helminth among different water source users. A total of 622 stool samples from school children of those families, which were using lands around longstanding-irrigation, recently constructed dam-irrigation and non-irrigated land, were processed by Kato thick smear and examined microscopically. The overall prevalence rate for intestinal parasites was $26.53 \%$, where as for $S$. mansoni infection it was only $5.95 \%$. A total of eight species of helminth parasites were identified; the highest being Ascaris lumbricoides $(10.45 \%)$ followed by Enterobius vermicularis $(8.52 \%)$. The prevalence and intensity of $S$. mansoni infection showed the highest rate in the longstanding areas $(13.73 \%)$, followed by the recently started irrigated areas from recently constructed dams $(6.18 \%)$ and the least in areas where the school children stay in un-irrigated area $(0.61 \%)\left(\chi^{2}=21.99, \mathrm{P}=0.000\right)$. We recommend that due attention should be given to health impacts of such agricultural interventions. The worm burden can be reduced by proper management of the water and the canal system like clearing the lithoral zones and the water canals to reduce the establishment of the intermediate hosts.
\end{abstract}

Key words: Eggs per gram, Intensity of infection, Long standing irrigation, Schistosoma mansoni, Schistosomiasis mansoni.

\section{INTRODUCTION}

In developing countries such as Ethiopia, infections due to intestinal parasites especially in children are still a public health problem (WHO, 1981). Ascaris lumbricoides, Trichuris trichiura, hookworms and Schistosoma mansoni (Rozendaal, 1997; WHO, 2002) are among the common causes of gastrointestinal discomforts.

Parasites are often encountered through unhygienic habits. Thus, regularly assessing the rate of parasitic infections in a given area could be a good indicator of the status of hygiene. All parasitic infections again flourish in nutritionally compromised or immune deficient patients, such as HIV/ AIDS patients. 
To reduce the dependency on rain-fed agriculture, the Ethiopian government is constructing small, medium, and large dams/reservoirs for irrigation development. More than 70 small reservoirs are constructed in Tigray during the last two decades with a primary purpose of supplementing the irrigation (De Wit, 2003; Tsehaye et al., 2007; Tadesse et al., 2008). On the other hand, the introduction of irrigation-based agricultural scheme has been associated with an increase in the prevalence of S. mansoni (Lo et al., 1988; Birrie et al., 1998; Kloos et al., 1998) Intestinal schistosomiasis is reported to be widely endemic in Tigray. Investigations, including the recent ones, reported that Schistosoma mansoni has covered quite many localities in the region with different prevalence rates: Maichew (1\%), Hiwane (4.2\%), Waja (34.2\%), Bele'at (38.3\%) Adwa (66\%), and Tumuga (87\%) (Birrie et al., 1994; Woldemicheal and Kebede, 1996; Alemayehu et al., 1998; Tadesse and Tsehaye, 2008; Tadesse and Beyene, 2009; Tadesse et al., 2009).

In this study, areas with long standing irrigation practices (more than 100 years of irrigation practices in Agulae), less than 30 years (e.g. Genfel river diversion in the mid 1980s; Wukro, 47 Kms North of Mekele), recently constructed dams and sites without irrigated lands are compared for the prevalence and intensity of intestinal helminth with special emphasis on S. mansoni infection. The finding of this study could be used to update the baseline data for mapping the distribution of schistosomiasis foci and future reference for designing and evaluating schistosomiasis control strategies.

\section{MATERIALS AND METHODS}

\subsection{Study area}

The study was conducted in Tigray, northern Ethiopia (Fig. 1). The study sites are located within $100 \mathrm{~km}$ radius toward north and south from Mekelle town, the capital of Tigray Regional State. Eight Primary Schools, namely, Megabit Selassa, Fana, Nekual Imni, Agulae, Mereb Mieti, Kokhi Azan, Hagere Selam and Gra Shitu were choosen for the study. Primary school children were used to index the assessment of community prevalence (Guyatt et al., 1999).

\subsection{Study Design}

A total of 622 school children (303 females and 319 males) were selected from the 8 representative schools (Table 1). The subjects were chosen randomly from their grade categories. Data collection was undertaken from April 2006 to March 2007. Specimens were 
collected on-the-spot. Students who were not able to pass stool during sample collection were advised not to bring their friends stool, but to report that they could not do it. Those who reported not able to pass were substituted by other students. The 622 samples were processed by Kato thick smear (Peters et al., 1980) in the field with in 1 hour of their collection and samples were transported to the laboratory at Mekelle University for microscopic examination. For each stool sample, only single slide was prepared by well trained expertise. All positive cases were treated after the identification of the parasite. Those study participants known to have $S$. mansoni infection were treated with Praziquantel $40 \mathrm{mg} / \mathrm{kg}$ body weight, single dose, while for other helminthic infections such as A. lumbricoides, T. trichiura and hookworm; 100mg BID Mebendazole were given for three days.

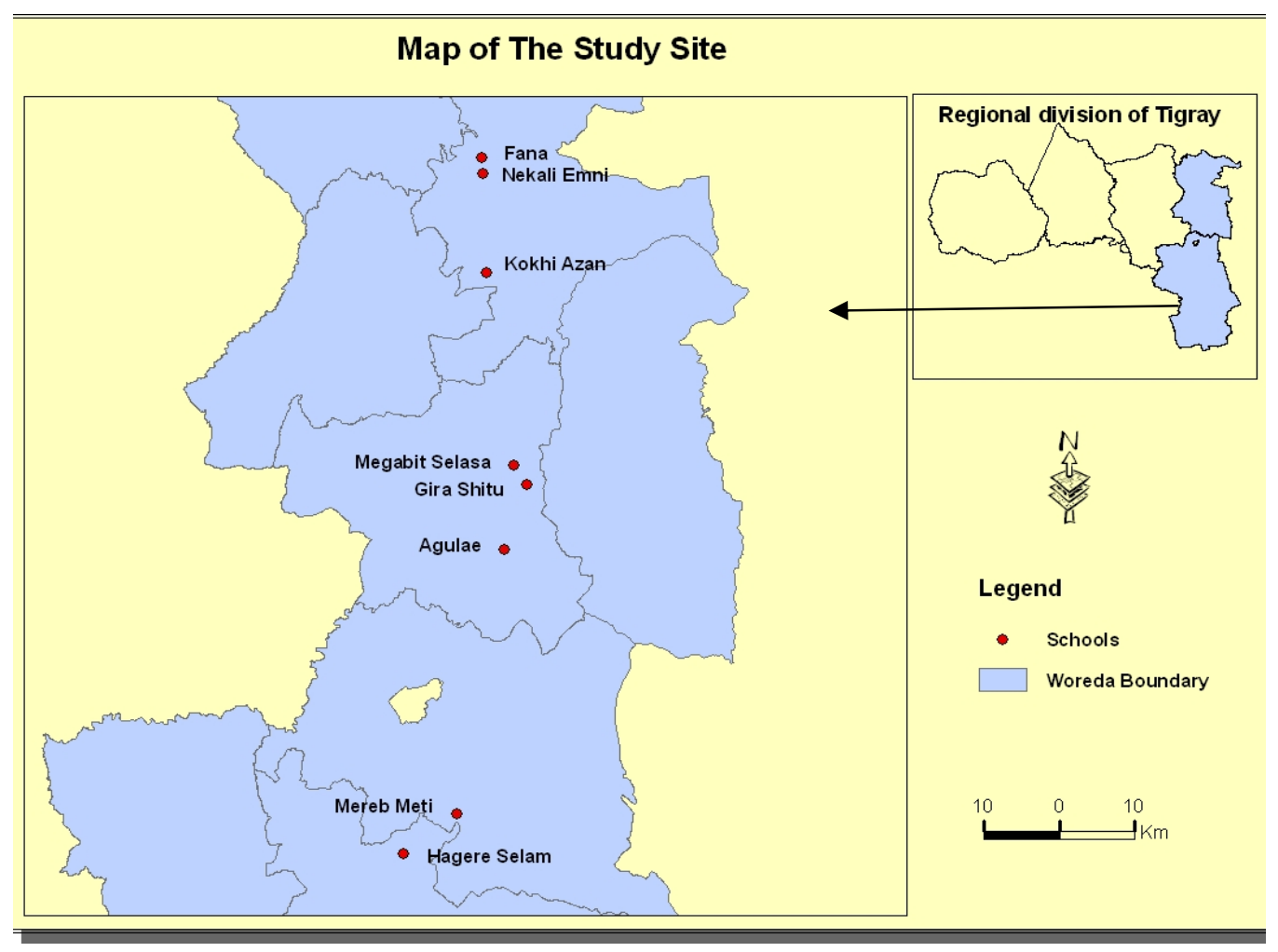

Figure 1. Map of study area, filled circles represent the location of the 8 primary schools.

Intensity of infection was estimated from the number of eggs per gram of faeces (epg). Based on egg counts, the intensity of different helminthic infections among children was categorized into light, moderate, and heavy using standard cut-off values (Montresor et al., 1999). Intensity of $S$. mansoni was classified into light (1-99 epg), moderate (100-399 epg) and heavy infections (> 400 epg). Similarly, the classification for A. lumbricoides was considered as light infection (1- 
$4999 \mathrm{epg}$ ), moderate (5000-49999 epg) and heavy (>50,000epg). Moreover, intensity of $T$. trichiura was classified as light (1-999 epg), moderate (1000-9999 epg) and heavy infections (> 10,000 epg). Finally, the classification of hookworm intensity was considered as light (1-1999 epg), moderate (2000-3999 epg) and heavy infections (>4,000epg). In the results, only intensity of $S$. mansoni was presented because the intensity in all others was light infection.

\begin{tabular}{|lllll|}
\hline Table 1. List of study schools, number of students examined, altitude and name of \\
nearby water bodies.
\end{tabular}

Snail samples were collected from water bodies using forceps to check the presence of appropriate snail intermediate host in the study area. Biomphalaria pfefferi were collected and squashed between two slides for checking the presence of cercariae of S. mansoni. The cercariae were identified morphologically by checking their bifurcated tail.

\subsection{Data analysis}

Data were entered into a computer and SPSS software (version 12) was used for Chi square test. The levels of significance of variables were evaluated at $95 \%$.

\section{RESULT AND DISCUSSION}

In the present study eight different species of parasites were identified from the school children (Table 2). Relatively the highest prevalence of infection was due to Ascaris lumbricoides (10.45\%) followed by Enterobius vermicularis (8.52\%). The prevalence of infection for one or more of intestinal helminthic parasite was 26. 53\% (ranging from $6.87-47.1 \%$ ), while infection due to $S$. mansoni was $5.95 \%$ (ranging from 0 to $27.45 \%$ ) (Fig. 2). The least intestinal helminth parasitic infection was recorded in Kokhi Azan Primary School (2600 masl) and the highest $(68 \%)$ was in Mereb Mieti with an altitude of 2227 masl. 
Generally, the prevalence of intestinal helminth parasitic infection recorded in this study was very low as compared to previous studies (Birrie et al., 1994; Woldemichael \& Kebede, 1996; Alemayehu et al., 1998, Erko et al., 1991; Birrie et al., 1997, Tadesse \& Beyene, 2009; Tadesse et al., 2009). This may be due to difference in location, awareness of the children, modification towards parasitic infection and the low prevalence of vectors.

In the study area, the prevalence of intestinal helminthic parasites specifically S. mansoni infection among different schools was highly significant $\left(\chi^{2}=90.78, \mathrm{P}=0.000\right.$ and $\chi^{2}=187.5, \mathrm{P}$ $=0.000$, respectively). This variation in infection might be associated with location of the school, altitude, behavior of children towards water body and presence of vector, etc.

The prevalence of infection due to one or more intestinal helminthic parasite showed significant variation among sexes $\left(21.78 \%\right.$ in females and $31.03 \%$ in males) $\left(\chi^{2}=6.825, \mathrm{P}<0.009\right)$ (Fig. 3). Similarly, the prevalence of $S$. mansoni was significantly higher in males than in females $\left(\chi^{2}=\right.$ $6.825, \mathrm{P}<0.009$ ). This finding was similar with the results of previous studies (see Lemma, 1969; Birrie et al., 1994; Woldemichael and Kebede, 1996). Higher prevalent rates among males than females have been reported from different parts of Ethiopia (Leykun, 1977, Birrie et al., 1998). This variation in infection is associated mainly to division of work in different communities and ethnic groups. Prevalence rate for S. haematobium among the Afar in the Awash Valley, for example, was reported to be twice as high among women as in men; because women collect aquatic plants in infected swamps on the Awash flood plain (Kloos et al., 1978).

\begin{tabular}{|lll|}
\hline $\begin{array}{l}\text { Table 2. Different species of helminthic parasites found in the } \\
\text { study population and their percentage prevalence. }\end{array}$ \\
\hline Species & Number + ve & \% prevalence \\
\hline A. lumbricoides & 65 & 10.45 \\
\hline E. vermicularis & 53 & 8.52 \\
\hline S. mansoni & 37 & 5.95 \\
\hline Taenia sp & 36 & 5.79 \\
\hline T. trichiura & 3 & 0.48 \\
\hline Hookworm & 2 & 0.32 \\
\hline Strongyloides stercoralis & 2 & 0.32 \\
\hline H. nana & 2 & 0.32 \\
\hline
\end{tabular}

The prevalence of infection with respect to age in both general intestinal helminth parasites and S. mansoni infection did not show significant variation $\left(\chi^{2}=1.87, \mathrm{P}<0.396\right.$ and $\chi^{2}=2.56, \mathrm{P}<$ 
0.258, respectively) (Fig. 4). In contrary to our findings, other research reports indicated significant difference in infection among different age groups (Erko et al., 1991; Birrie et al., 1997; Alemayehu et al., 1998; Tadesse and Beyene, 2008). Fig. 4, age specific prevalence of $S$. mansoni infection; the highest being the age group 10-14 years, which is similar to the above findings.
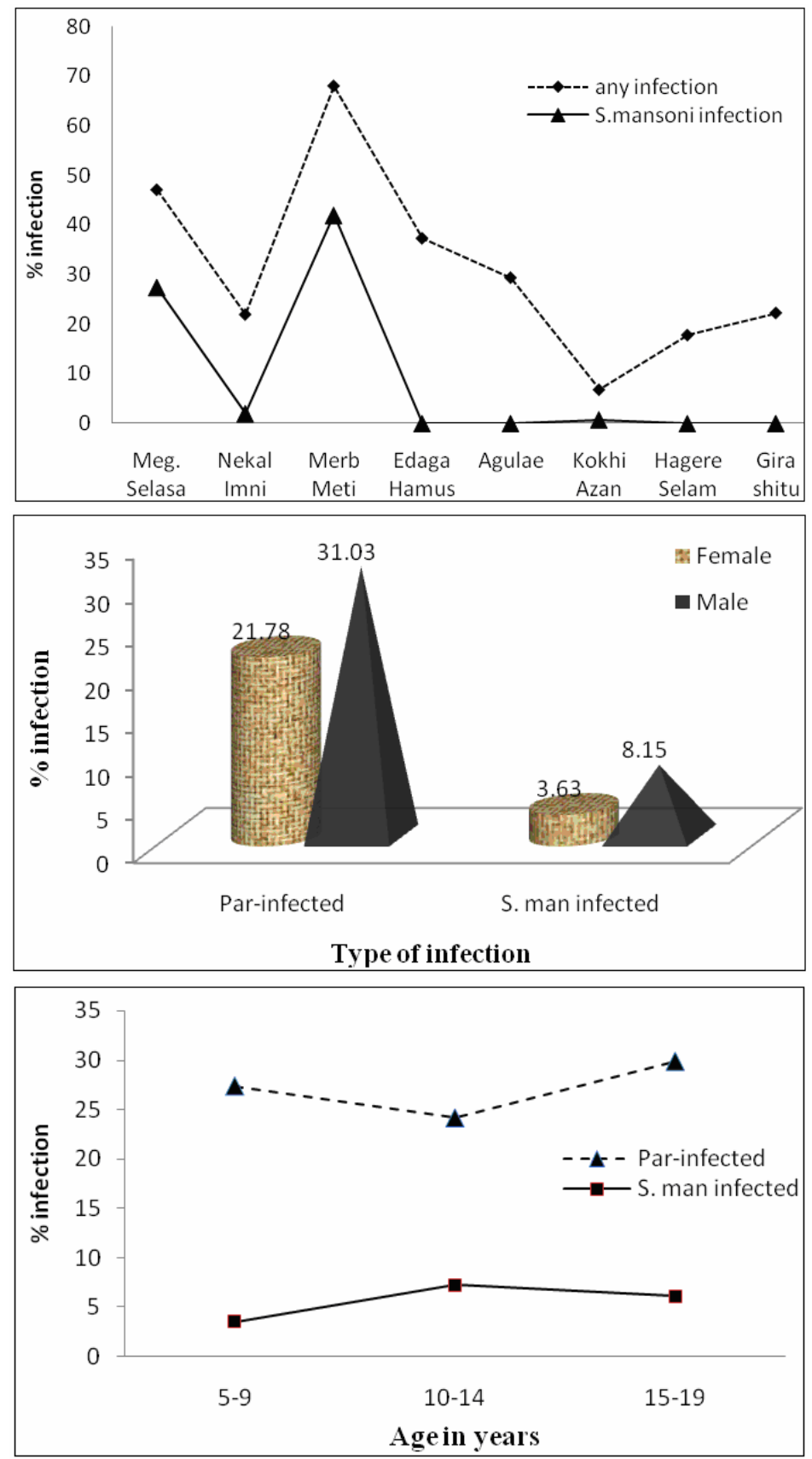

Figure 2. Comparison of infection due to $S$. mansoni and other helminth infection in the school children.

Figure 3. Prevalence of S. mansoni and other helminth infections among sex.

Figure 4. Percentage of infection among different age groups. 


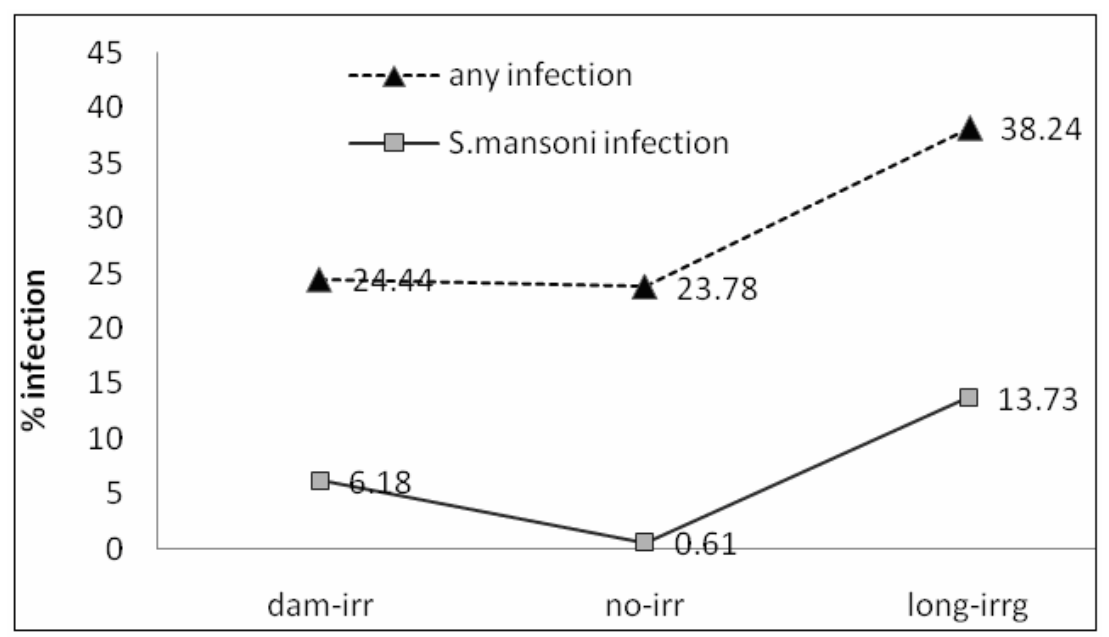

Figure 5. Comparison of infections due to $S$. mansoni and other intestinal helminth infections in school children of different water source users.

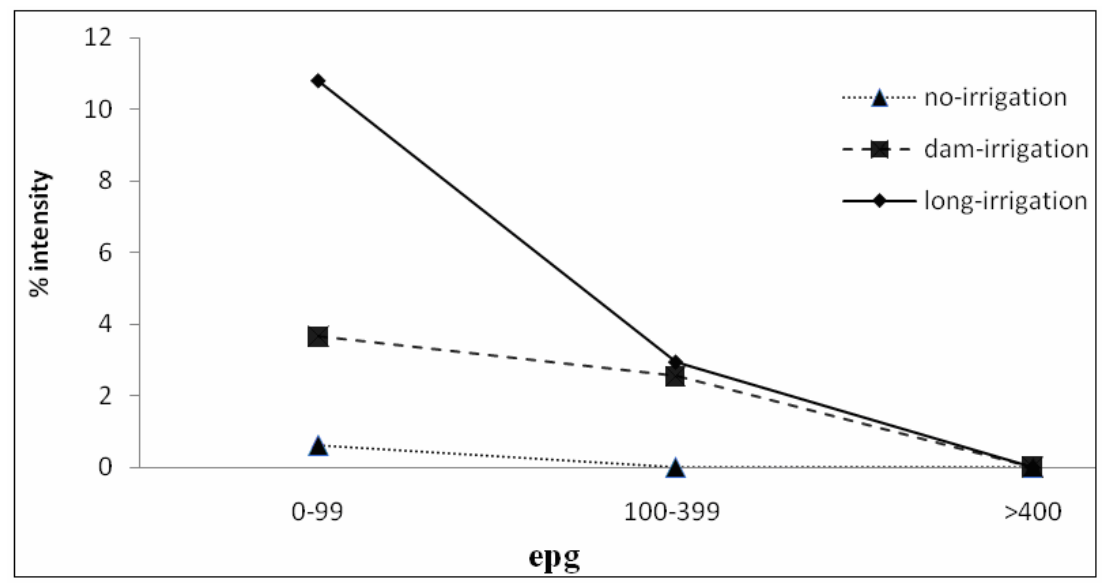

Figure 6. Intensity of S. mansoni infection among school children in different irrigation schemes.

The prevalence for one or more parasitic infection and specifically to $S$. mansoni infection with respect to water source user is presented in Fig. 5. The prevalence of S. mansoni showed the highest infection rate in the longstanding irrigated areas $(13.73 \%)$, followed by the recently introduced irrigation schemes from recently constructed dams $(6.18 \%)$ and the least in areas where the school children stay in un-irrigated area $(0.61 \%)$. The distribution of intestinal parasitic infections in association to water source still showed significant variation $\left(\chi^{2}=8.605, \mathrm{P}\right.$ $<0.014)$ with highly significant variation in $S$. mansoni infection $\left(\chi^{2}=19.42, \mathrm{P}=0.000\right)$. Similar results were reported from Tigray by Alemayehu et al. (1998), Tadesse and Tsehaye (2008) and Tadesse and Beyene (2009). In agreement with this, longitudinal studies in other parts of Ethiopia had also indicated an increase in the prevalence of schistosome infection with the age of 
the irrigation scheme (Tedla et al., 1986; Abebe et al., 1995; Birrie et al., 1995). Reports from Egypt had also shown an increase in prevalence from $0.05 \%$ to $60 \%$ within less than five years following the introduction of an irrigation scheme into a region (Farid, 1971).

The prevalence of $S$. mansoni infection is associated with prevalence of the snail intermediate hosts (Markell, 1971) (see Table 3). Lemma (1969), Kloos et al. (1978) and Kloos (1985) also observed that the continuing large-scale agricultural use contributes to the spread of schistosomiasis. On the other hand, the fact that the major human intestinal helminth parasites such as hookworm, Ascaris and Trichuris larvae and ova require humid environments indicates that water source could still be a factor for transmission of intestinal parasites (Kloos et al., 1981). The findings of S. mansoni were also cross checked by comparing the distribution of the snail intermediate host, Biomphalarai pfeifferi (Table 3).

Table 3. Results of malacological survey.

\begin{tabular}{|llll|}
\hline No. & Water body searched for Biomphalriai pfeifferi & Snails & Cercaria infected snails \\
\hline 1 & Endagebriel dam & Absent & Absent \\
\hline 2 & Bokoro dam & Absent & Absent \\
\hline 3 & Hizaeti-Wedicheber dam & Present $(++)$ & Present $(+)$ \\
\hline 3 & Lailay- Wukro dam & Absent & Absent \\
\hline 4 & Wukro river and irrigation canals & Present $(++)$ & Present $(+)$ \\
\hline 5 & Agula'e river and irrigation canals* & Absent & Absent \\
\hline 6 & Mai Wuhug & Present (+) & Absent \\
\hline 7 & Korir dam & Absent & Absent \\
\hline 8 & Gereb Mihiz dam & Present $(+)$ & Absent \\
\hline 9 & Tsinkanet dam & Absent & Absent \\
\hline
\end{tabular}

- = All weeds and grasses in the canals were removed, + indicates presence but very high quantity, ++ indicates the presence in high quantity.

In the present study, only light and moderate intensity of S. mansoni infections were recorded, with no heavy infection $\left(\chi^{2}=21.99, \mathrm{P}=0.000\right)$ (Fig. 6). The highest light intensity of $S$. mansoni infection was in the longstanding irrigated sites followed by the recently introduced irrigation practices. In areas where there is no irrigated land (sites with rain fed agriculture), the prevalence and intensity of $S$. mansoni infection was very low, which is similar to previous studies (Alemayehu et al., 1998; Tadesse and Tsehaye, 2008; Tadesse and Beyene, 2009). In general, our findings demonstrate the impact of water- based development in creating favorable condition for intestinal helminth parasitic infections especially for S. mansoni. 
The interesting finding of this study is the absence of S. mansoni infection in Agulae an area with irrigation history of more than 100 years. Furthermore, it is reported that S. mansoni has high prevalence (27.45\%) in Megabit Selasa Primary School (Wukro), which is only $10 \mathrm{~km}$ away from Agulae and with similar environmental conditions.

\section{CONCLUSION}

It can be concluded that the increased prevalence rate of $S$. mansoni infection with the increased introduction of irrigation schemes will be of great public health concern unless appropriate control measures are designed. Lessens can be learned from Augulae, a longstanding irrigation area for more than 100 years and no Biomphalarai pfeifferi in the canals. Thus, removing the intermediate host by periodic clearing of the irrigation canals might have resulted getting rid of schistosomiasis. To reduce the overall parasitic infections, proper management of the water and the canal system is recommended. The provision of safe water supply and latrines can also contribute to deter schistosomiasis transmission in endemic areas by reducing the human-water contact, as significant reduction in the prevalence and intensity of infections by S. mansoni which has already been reported from elsewhere by water supply provision alone (Jordan et al., 1980).

\section{ACKNOWLEDGEMENTS}

This study was financially supported by the Mekelle University Inter University Cooperation project (MU-IUC). We would also like to acknowledge MU-IUC management staff, school directors and students of the study area. This study would not be materialized without the assent and willingness of the study participants.

\section{REFERENCES}

Abebe, F., Tedla, S., Birrie, H \& Medhin, G. 1995. Transmission dynamics of S. mansoni in an irrigation setting in Ethiopia. Ethiop. J. Health Dev., 9:147-156.

Alemayehu, T., Ye-ebiyo, Y., Ghebreyesus, T.A \& Witten, K.H. 1998. Malaria, Schistosomiasis, and intestinal helminths in relation to micro-dams in Tigray, northern Ethiopia. Parassitologia, 40: 259-267. 
Assefa, T., Weldemicheal, T \& Dejenie, A. 1998. Intestinal parasitism among students in three localities in South Wollo, Ethiopia. Ethiop. J. Health Dev., 12:231-235.

Birrie, H., Tedla, S., Tilahu, G., Kloos, H \& Eshete, H., 1998. In: Birrie, H., Tedla, S \& Jemaneh, L (eds.), Schistosomiasis in Ethiopia and Eritrea. Addis Ababa University, Addis Ababa.

Birrie, H., Medhin, G., Erko, B., Beshah, G \& Gemechu, T. 1997. Intestinal helminth infections among the current residents of the future Finchaa Sugar Plantation area, Western Ethiopia. Ethiop. J. Health Dev., 11:219-228.

Birrie, H., Weldemichael, T., Redda, A \& Chane, T. 1994. The status of S. mansoni and snail hosts in Tigray and northern Wollo regions, northern Ethiopia. Ethiop. Med J., 32:245254.

De Wit, J. 2003. Stuwmeren in Tigray (Noord-Ethiopië): kenmerken, sedimentatie en sedimentbronnen. M.Sc. thesis, Department of Geography, K.U. Leuven (unpubl.).

Erko, B., Tedla, S \& Petros, B. 1991. Transmission of intestinal schistosomiasis in Bahr Dar, Northwest, Ethiopia. Ethiop Med. J., 29:199-211.

Farid, M. A. 1971. The Aswan High Dam Development Project: In: Stanley, N. F. and Algers, M. P. (eds.), Manmade lakes and human health, Academic Press, London, New York, San Francisco, Toronto, pp.345-362.

Figuerola, J \& Green, A. J. 2002. Dispersal of aquatic organisms by water birds: a review of past research and priorities for future studies. Freshwater Biology, 47:483-494.

Guyatt, H.L, Brooker,S \& Donnelly,C. A. 1999. Can prevalence of infection in school aged children be used as an index for assessing community prevalence? Parasitology, 118: 257-268.

Jemaneh, L. 1999. Intestinal helminth infections in school children in Gonder Town and surrounding areas, northwest Ethiopia. SIENT: Ethiop. J. Sci., 22:209-220.

Jemaneh, L. 1977. Intestinal helminth infection in schoolchildren in Adarkay District, North Ethiopia, with special reference to schistosomiasis mansoni. Ethiop. J. Health Dev., 11: 289-294

Jordan, P., Christie, C.D \& Urban, G.O. 1980. Schistosomiasis transmission with particular reference to possible ecological and biological methods of control. Acto Tropica, 37: 95-120. 
Kloos, H., Tsegaye, F \& Tedla, S. 1998. In: Birrie, H., Tedla, S \& Jemaneh, L. (eds.), Schistosomiasis in Ethiopia and Eritrea. Addis Ababa University, Addis Ababa.

Kloos, H. 1985. Water resource development and schistosoma ecology in the Awash Vally, Ethiopia. Soc. Sci. Med., 20:609-625.

Kloos, H., DeSole, G \& Lemma, A. 1981. Intestinal Parasitism in semi-nomadic pastoralists and subsistence farmers in and around irrigation schemes in the Awash Valley, Ethiopia, with special emphasis on ecological and cultural associations. Soc. Sci. Med., 15: 457469.

Kloose, H., Aklilu, L \& DeSole, G.1978. Schistosomiasis mansoni distribution in Ethiopia: a study in medical geography. Ann. Trop. Med. Parasitol., 72: 461-470

Kloos, H., Lemma, A., Kibru, B., Gebre, A., Mazengia, B., Feleke, G \& DeSole, G. 1980. Intestinal Parasitism in migrant farm labor populations in irrigation schemes in the Awash Valley, Ethiopia, and in major labor source areas. Ethiop. Med .J., 18: 52-61.

Lemma, A. 1969. Bilhariasis in Awash Valley. I. An Epidemiological study with special emphasis on its possible future economic and public health importance. J. Ethiop. Med., 7:147-176.

Lemma, A. 1968. Parasitological Survey of Addis Ababa and Debrezeiet school children, with special emphasis on bilharziasis. Ethiop. Med. J., 6: 61-71.

Lo, C.T., Kloos, H \& Birrie, H. 1988. Schistosomiasis. In: Zein Ahmed and Kloos, H. (eds.), The Ecology of Health and Disease in Ethiopia, Addis Ababa: EMPDA Press, pp.196- 207.

Markell, E.K \& Voge, M. 1971. Medical Parasitology. ${ }^{\text {rd }}$ Ed. W.B. Sounders Company. Philadelphia London. Toronto, pp.171-173.

Montresor, A., Gyorkos, T. W., Crompton, D. W. T., Bondy, D. A. P \& Savioli, L. 1999. Monitoring helminth control programs. Guideline for monitoring the impact of control programs aimed at reducing morbidity caused by soil-transmitted helminthes and schistosomes, with particular reference to school age of children. WHO/ CDS / CPC / SIP/99.3. WHO, Geneva.

Peters, P.A., Alamy, M.E., Warren, K.S \& Mahmoud, A.A.F. 1980. Quick Kato Smear for field quantification of Schistosoma mansoni eggs. Am. J. Trop. Med. Hyg., 29:217- 219.

Rozendaal, J .R. 1997. Vector Control Methods for use by Individuals and Communities. WHO, Geneva, 337- 356. 
Tadesse Dejenie \& Tsehaye Asmelash 2008. The Impact of Irrigation on the prevalence of intestinal parasite infections with emphasis on schistosomiasis in Hintallo-Wejerat, North Ethiopia. Ethiopian J. Health Sci., 18: 33 -45.

Tadesse Dejenie, Tsehaye Asmelash, L. De Meester, Afework Mulugeta, Abreha Gebrekidan, Risch, S., Pals, A., Van der Gucht, K., Vyverman, W., Nyssen, J., Deckers, S \& Declerck, S. 2008. Limnological and ecological characteristics of tropical semi-arid highland reservoirs in Tigray, Northern Ethiopia. Hydrobiologia, 610:193-209.

Tadesse Dejenie \& Beyene Petros 2009. Irrigation Practices and Intestinal Helminth Infections in Southern and Central Zones of Tigray. Ethiopian J. Health Dev., 23: 48 - 56.

Tadesse Dejenie, Tsehaye Asmelash \& Mekonnen Teferi. 2009. Intestinal Helminthes Infections and Re-Infections with Special Emphasis on Schistosomiasis Mansoni in Waja, North Ethiopia. Momona Ethiopian Journal of Science, 2(1): 4-16.

Tedla, S \& Yimam, M. 1986. Schistosomiasis at the Wongi-Shoa Sugar Estate during two decades (1964-1985). Afr. J. Sci. Tech., 1:1-18.

Tsehaye Asmelash, Tadesse Dejenie, Declerck, S., Nyssen, J., Van der Gucht, K., Risch, S., Rousseaux, S., De Wit, J., Afework Mulugeta, Nigussie Haregeweyn, Abraha Gebrekidan, Poesen, J., Deckers, J., Vyverman, W \& De Meester, L. 2007. Ecological atlas of reservoirs in Tigray, Northern Ethiopia: Tigray Livelihood Papers No. 4, VLIR, Mekelle University IUC Programme and Zala-Daget Project, 80.

Woldemichael, T \& Kebede, A. 1996. Newly identified endemic areas of schistosomiasis mansoni in Tigray, north Ethiopia. Ethiop. Med. J., 34:73-81.

World Health Organization.1981. Intestinal protozoa and helminth infection. WHO Tech. Report, No.666, Geneva.

World Health Organization. 2002. Prevention and control of schistosomiasis and soil transmitted helminthiasis. WHO Tech. Report, No. 912, Geneva. 